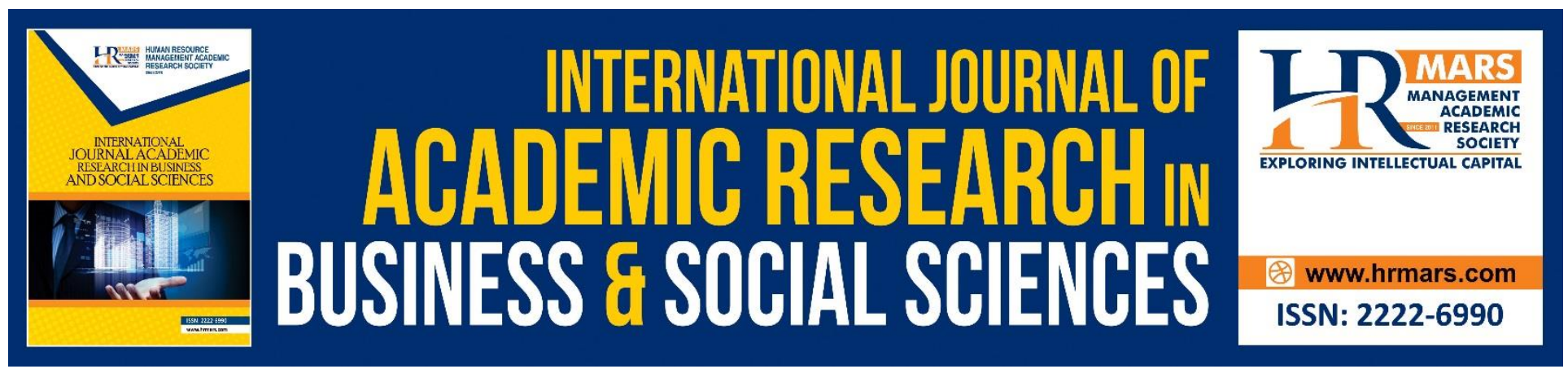

\title{
From Knowledge Retention to Knowledge Transfer
}

\author{
Khuzaimah Mohd Shah, Norhayati Hussin
}

To Link this Article: http://dx.doi.org/10.6007/IJARBSS/v8-i9/4595

DOI: $10.6007 /$ IJARBSS/v8-i9/4595

Received: 21 August 2018, Revised: 29 September 2018, Accepted: 04 October 2018

Published Online: 13 October 2018

In-Text Citation: (Shah \& Hussin, 2018)

To Cite this Article: Shah, K. M., \& Hussin, N. (2018). From Knowledge Retention to Knowledge Transfer. International Journal of Academic Research in Business and Social Sciences, 8(9), 329-334.

Copyright: (c) 2018 The Author(s)

Published by Human Resource Management Academic Research Society (www.hrmars.com)

This article is published under the Creative Commons Attribution (CC BY 4.0) license. Anyone may reproduce, distribute, translate and create derivative works of this article (for both commercial and non-commercial purposes), subject to full attribution to the original publication and authors. The full terms of this license may be seen at: http://creativecommons.org/licences/by/4.0/legalcode

Vol. 8, No. 9, September 2018, Pg. 329 - 334

Full Terms \& Conditions of access and use can be found at http://hrmars.com/index.php/pages/detail/publication-ethics 


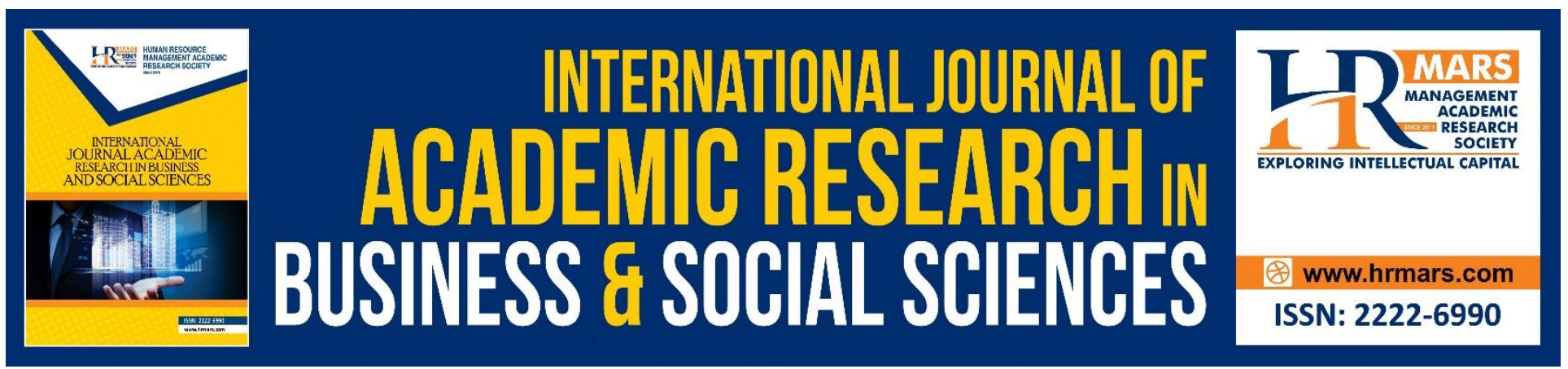

\title{
From Knowledge Retention to Knowledge Transfer
}

\author{
Khuzaimah Mohd Shah, Norhayati Hussin \\ Faculty of Information Management, Universiti Teknologi MARA, UiTM Selangor, Malaysia
}

\begin{abstract}
Information is a vital factor used by librarian, scientists and other information professionals and practitioners, in the library or any organization to make decision making, to prepare plans and strategies, to execute activities and services whether it is formal or informal knowledge to achieve its goals and objectives. Managing the valuable knowledge is now being seen as the mandatory action to be taken within many organizations so that this valuable resources can be used and accessed by anyone from anywhere, at any time. This need to be used and managed properly, so that it can stimulate new innovation, develop the levels of productivity, consistently ensure the quality of standard in order to compete the relative level of competitiveness in the organization. In this paper, it discussed some of the contemporary issues that are related in the world of information professionals. Knowledge retention and knowledge transfer have been risen in the recent times within the information society which involving the information management, knowledge management to the globalization of information services. Some issues and measurement action can be done to in order implement knowledge retention and knowledge transfer within the organization. Keywords: Knowledge Retention, Knowledge Transfer, Information Management, Knowledge Management
\end{abstract}

\section{Introduction}

Nowadays, knowledge has become an enormous tool and increasingly being recognized as the new strategic and crucial concept in the organization. Knowledge is a power, in which one person need to have and maintain it as an advantage to oneself. Thus, with you holding the specific knowledge, it will helps to makes him or her to become an important asset to the organization.

According to Grant (2013), he defined knowledge as an intangible resource, and it combines with other firm resources which are examples like financial and physical to create capabilities. The sources of knowledge can be categorized as either tacit (implicit) or codified (explicit). Tacit knowledge is a form of non-verbalized knowledge which is gained through personal's experience and practice, which is a knowledge that reside in an individual's head. It can be derived by learning new language, creating innovation, leadership skills, emotional intelligence and aesthetic sense are some of the example of tacit knowledge that can be cultivated but not taught. In the other hand, the definition of codified knowledge can be seen as a knowledge that can be readily circulated, accessed, saved in database and verbalized and easily can be transmitted to others for fasts information access systems. It is in 
INTERNATIONAL JOURNAL OF ACADEMIC RESEARCH IN BUSINESS AND SOCIAL SCIENCES Vol. 8, No. 9, Sept. 2018, E-ISSN: 2222-6990 @ 2018 HRMARS

transferrable format and in systematically recognized language in which we can retrieved it from the manuals, documentations, procedures, product design and much more. This implicit and explicit knowledge are both inter-related, mutually complementary in a sense that we need one to use the other in order to manage our valuable knowledge resources.

Hoarding the knowledge for a long time to oneself has become negative practiced in the organization. This is where we called it knowledge loss and knowledge retention. The knowledge loss has become one of the significant factor in which giving the organization the great impact when facing the difficulty in economic turndown and rival competitions. Several aspect such as layoffs and retirement of valuable staffs, merging and acquisition can affects to the losing of their sustained competitive advantages. It is important for the organization to know very well the consequences of losing their valuable knowledge. People who are retiring, leaving and moving on to a new company will resulted the loss of valuable knowledge and it has to be continuous and consistently monitored by implementing the concept of sharing knowledge from the brains of the employees.

Thus, to avoid the loss and retention of this specific knowledge, some measurable steps need to be done in action in order to move forward in creating a good significance of retaining knowledge in the organizations. This is the core of knowledge management practices to take place, in which implementing the good solution of knowledge transfer. This new paradigm and method will let the knowledge within the organization to be shared in order for the knowledge itself to grow and become stronger and more competitive advantage among their organization.

\section{Knowledge Retention: Challenges and Strategies}

It is very important to fully understand the consequences that can affects by losing the valuable knowledge to the organizations. It has become a critical factors for the organization to strive in their world of competition in order to sustain successfully. According to Perrott (2007), the definition of knowledge loss can be defined as the intentional or unintentional evaporation of knowledge that accumulates from learning and from individual and collective actions. Several factors such as ineffective organizational routines and memory (deHolan and Philips, 2004) and employee turnover (Martins and Meyer, 2012). An organization which is lacking due to the practical mechanisms in such not remembered what has worked and what did not, which can lead to repetitive failures of practices. Different effects can lead when the organization did not follow the correct routines and steps that can lead to misleading the valuable knowledge being misinterpreted to the organization. In addition, employee's resignations, retirement, company restructuring and employee's layoffs, employees reluctant to engage in knowledge sharing and daily employee's workloads are the major driver factors that can lead to the knowledge loss within the organization itself.

Knowledge loss can bring up to significant and vast performance implications for an organization. It will show that strategies that target the retention of tacit knowledge and within the firm activities are effective to mitigate the knowledge loss. The tacit knowledge should be disseminated and diffused throughout the organization. Moreover, the results will improve strategic coordination among organization, can develop existing capabilities through different networking strategies and more effective networks, and will transform these capabilities into effective organizational routines. Building more effective networks combining weak and strong ties would increase the dissemination and diffusion of knowledge across the network. Additionally, the use of mobility, cross-functional 
INTERNATIONAL JOURNAL OF ACADEMIC RESEARCH IN BUSINESS AND SOCIAL SCIENCES Vol. 8, No. 9, Sept. 2018, E-ISSN: 2222-6990 @ 2018 HRMARS

training, and rotation programs would increase tacit knowledge retention and reduce knowledge loss.

Thus to avoid this from happened, we need to take corrective action and strategies to implement the knowledge and employees retention from being loss. Capturing the valuable knowledge required the identification of critical knowledge for organization's business operations and the organization's team management to evaluate and decide the level of knowledge criticality whether it is valuable for them to retrain for the use, packaging and dissemination of that particular knowledge.

Based from the research done by Wan Fakeh, Shahibi \& Hussin (2015), it is clearly shown the result that can lead to the influences of retention knowledge workers in the organization. In this paper, a good retention practices has become an important insight on how the organization managing and treating their employees and staffs effectively and efficiently in a good manner. Three main drive factors that has been discussed are the motivation, job satisfaction and the payable satisfaction which are satisfactorily agreed and accepted by the employee and staffs in order for them to work and stay longer in the organization. This significant factors are the major contribution for the organization to works together aligned with their employee to achieve their organization's key goals and objectives.

\section{Knowledge Transfer: Challenges and Strategies}

Knowledge-sharing and knowledge transfer is a process which the valuable and targeted knowledge is retrieved and organized from the sources, and is being directed and transferred onto the employees of the organization. According to Argote and Ingram (2000), they defined knowledge transfer in organizations as the process through which one unit (group, department, or division) is affected by the experience of another. In addition to the definition of knowledge transfer, the term can also be applied to transfer between individuals, individuals to groups, between groups and across groups and from individuals to an explicit (Alavi \& Leidner, 2001).

Based from the research done by Mohamad Hassan, Muhamad Noor, and Hussin (2017), it shows several factors that influenced knowledge transfer within organization. The main factors are derived from social and culture values that bring the motivation and willingness to share the knowledge through the employees in the organization that can bring the high significant impact towards business performance. The second factors that has been discussed was the technology that can helps to boost the knowledge transfer by established the communication tools as the driver for the organization to enhance the best practice in the work process within the organization. Another factor was the use of language that enable the process of knowledge transfer to be implemented in the organization. Through shared language, it will help to facilitate and motivate the employees to use knowledge transfer and will reduce the barriers and the limitation to the process of transfer it. Addition to this significant factors, building up the trust and relationship between the employees and within the organization in a certain level.

There are many ways for an organization to identify, store and transfer the valuable knowledge. Some of the strategies will work better in one organization compared to another. The challenges are to identify and develop complementary ways to manage and transfer knowledge in an organization. There are several challenges and barriers that can be the factors affected while applying and managing the knowledge transfer practices in the organization. First of all, it can be derived from the 
INTERNATIONAL JOURNAL OF ACADEMIC RESEARCH IN BUSINESS AND SOCIAL SCIENCES Vol. 8, No. 9, Sept. 2018, E-ISSN: 2222-6990 @ 2018 HRMARS

coordination aspects within the organizations. Issues such as lack of competencies and expertise in applying the knowledge and the level of experience involved, unmanageable of coordination and the integration of multiple knowledge resources in the organization and mostly was on the financial and infrastructure management in order to execute the implementation of knowledge transfer in the organization. Secondly, we can described the communication barriers as the challenges to implying the successfulness of knowledge transfer. Factors such as the differences language used by the team members that will be hard to understand and leading to misunderstandings. Plus, the poor communication will lead to the inadequate of understanding of their customer's business. Thirdly, some aspect of cultural challenges that can be the main factors that prevent to implement the process of knowledge transfer in the organization. There are issue such as difference cultural diversity and political philosophy which somehow brings and affect negatively between the interactions with the management and the employees in the organization. There are lack of trustworthy and selfmotivation to practice transfer and sharing the knowledge.

In order to overcome those barriers and challenges, some initiatives can be implement the successfulness of knowledge transfer in the organization. The management together with the employees can work together to improve the effectiveness of the information management practices. First of all, through the coordination aspects, the organization must be employed and enabling different technologies to ensure the successfulness of sharing their knowledge resources efficiently. Nowadays, the se of Share Point knowledge-based portal is a necessities which can provides the various knowledge and information to all employees in the organization. With this organized and coordinated project knowledge portal and databases, it will provides the accurate, complete and up-to-date knowledge as possible to the organization. The coordination need to be adopt with the requirements of technology and modelling process of the knowledge transfer mechanism to be put in first place. Organization should defined the responsibilities and to implement the high-end environment in order to develop the employee's high competencies in the organization. Secondly, the strategies that can be done to overcome the communications issues by increasing and improving the awareness among the employees in the organization. Various communication tools and method such as document management databases, video conferencing, e-mails, and instant messaging can support to achieve better face-to-face and online interaction. This centralized communication structure will helps to provide better services for sharing mechanism to meet up the requirement and solutions. They can try to implement a knowledge database which indeed works as a centralized knowledge repository shared by the stakeholders of the organization. Finally, as for the solutions and strategies to be used in the cultural issues are by nurturing the cultural bridges by promoting the trust, in the case try to understand the language of the clients, and established the relationships among the employees. This will creating a common culture within the organization itself. In addition, establishing the Community of Practice (COP) will helps the within the organization to share information and that can be stored and transmitted from one person (or a group) to another person or group.

\section{Conclusion}

This paper has identified and analysed the issues and strategies that can used for the implementation of knowledge retention and knowledge transfer in the organization. The existence of up-to-date and high-quality knowledge is crucial for organizations competitiveness and sustainability. Therefore, maintaining the knowledge retention and knowledge transfer need to deliver their products and 
INTERNATIONAL JOURNAL OF ACADEMIC RESEARCH IN BUSINESS AND SOCIAL SCIENCES Vol. 8, No. 9, Sept. 2018, E-ISSN: 2222-6990 @ 2018 HRMARS

services. Successful knowledge retention and transfer will become an effective process of building and employing an organizational memory in order to capture the process in the organization. As a conclusion, wide market economy in the organization will experienced the significant challenges in implementing the practical approaches together in order to mitigate any risks while balancing the knowledge retention and knowledge transfer.

\section{References}

Alavi, M., \& Leidner, D. (2001). Review: Knowledge Management and Knowledge Management Systems: Conceptual foundations and research issues MIS Q. (Vol. 25, pp. 107-136).

Argote, L., \& Ingram, P. (2000). Knowledge Transfer: A Basis for Competitive Advantage in Firms. Organizational Behavior and Human Decision Processes, 82(1), 150-169. doi:10.1006/obhd.2000.2893.

Deholan, P. and Phillips, N. (2004). Remembrance of Things Past? The Dynamics of Organizational Forgetting. Management Science, Vol. 50 No. 11, pp. 1603-1613.

Grant, R.M. (2013). Contemporary Strategy Analysis: Text and Cases. 8th ed. Malden Blackwell Publishers.

Martins, E.C. and Meyer, H.W.J. (2012). Organizational and Behavioral Factors That Influence Knowledge Retention. Journal of Knowledge Management, Vol. 16 No. 1, pp. 77-96.

Perrott, B.E. (2007). A Strategic Risk Approach to Knowledge Management. Business Horizons. Vol. 50. No. 6, pp. 523-533. 